\title{
Corporate social responsibility developments in post-communist countries: Towards organisations' social legitimacy
}

\author{
प⿴囗十口प \\ Kaja Tampere \\ ORCID: 0000-0003-0817-3339 \\ TALLINN UNIVERSITY, ESTONIA
}

DOI: $10.19195 / 1899-5101.12 .1(22) .4$

\begin{abstract}
The aim of the paper is to introduce corporate social responsibility (CSR) as an organisation's management and stakeholders' relations tool in post-communist countries for ensuring the organisation's social legitimacy. The article discusses how understanding the interdependence between the organisation and society helps to support the organisation to develop social legitimacy and therefore ensure its sustainability. The general research problem in this article is connected with the societal context of studied organisations: how CSR could be positioned and managed in a post-communist society to avoid a rebuff against an organisation's CSR activities. The topic of this paper is approached through three research questions: how post-communist organisations see the CSR position in the organisation, how social legitimacy is acknowledged and defined, and finally to what extent CSR is seen as a tool for ensuring social legitimacy. For the research, seven Estonian organisations' representatives with management responsibility were interviewed to find out their thoughts and ideas about CSR and social legitimacy.
\end{abstract}

KEYWORDS: CSR, social legitimacy, business and society, management, post-communist countries.

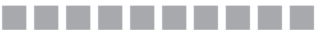

\section{INTRODUCTION}

During the past few years, corporate social responsibility (CSR) as a part of organisational lifestyle has grown and developed in post-communist countries. Today we can say that many organisations are engaging CSR in this type of society after principal political and economic changes in Europe in the beginning of the 1990s. Through CSR activities, organisations in the new societal environment are able to interact, play an important role and take part in societal everyday life. These organisations can be more trustworthy because of their attitude towards social legitimacy. 
The trend to practise CSR and strategically develop social legitimacy has also become important for organisations to be sustainable, have social support and the power to grow.

Being socially responsible would be beneficial also in the organisations' decisionmaking processes and in the actions to show organisational values. Organisations who have engaged CSR activities into their management culture are also more valuable in the eyes of employees, stakeholders, shareholders and media.

\section{DEFINING CORPORATE SOCIAL RESPONSIBILITY}

Although the term CSR was introduced several decades ago, it still lacks one broadly accepted definition. CSR is explained differently in various sources. In some sources CSR focuses on external groups of a company, while others emphasise its internal environment. Some definitions also deal with stakeholder interests, while others refer to much wider perspectives, such as the local community, environment, society and so on (Tampere, 2013).

Although CSR is elective, it can still be compulsory by the legislative aspects. Because of this, CSR is divided into three:

- philanthropic obligations - electively taken obligations, such as sponsorship and being part of charity funds;

- ethical obligations - these are obligations that are related to the expectations towards society and that are not specified by the law;

- the legitimate and economic responsibilities - actions that can be required by law (Brusseau, 2011).

When theoretically CSRs are divided into three, they cannot be separated from each other in reality, especially when we are looking at some bigger organisations. Based on these three types of responsibilities, we can define CSR for the present study as follows: CSR in post-communist societies is the combination of ethical entrepreneurship, active citizenship, learning organisations and charity. The historical environment and societal memory create some ideological contradictions in the organisations' practice, because the communist era has not been deleted from the memories of the people and the organisation. But on the other hand, this experience from the past can also be an inspiration to fulfil one's dreams about the future.

The concept of CSR has also attracted a range of criticisms from different authors. Some are critical of the concept itself, others are concerned that there is no single agreed definition of CSR. It depends on the demographic, political, and moral (ethical) background of the person or organisation (Pirsch et al., 2007). Any corporation's legitimacy depends on its ability to meet the expectations of a diverse array of stakeholders (Morsing, 2005). For organisations that operate in postcommunist and also rapidly changing societies, CSR is necessary because it helps 
to learn and grow, and to find their new identity, mission and values, in accordance with the rapid changes in their environment.

\section{CO-EVOLUTION OF SOCIETY AND ORGANISATION}

Holmström (2005) has explained the need for social responsibility with the idea of co-evolution of organisation and society. It is especially important from the postcommunist society approach. To illustrate the co-evolution of society and organisation, Holmström (2005) applied three different perspectives on the character and evolution of the society: the general perspective of modernity, the more specific dimension of society's differentiation, and finally the political form of regulation. Each of these perspectives reveals a co-evolution of the interrelations between organisation and society-at-large (Holmström, 2005). Holmström's three dimensions help us understand the evolution/development of organisations and their operation, plus her approach explains CSR's societal focus. Holmström's third dimension is the form of political regulation, and this is especially important in the post-communist approach. During absolutism, organisations are constituted as institutions as part of a whole in guilds. Gradually, the organisation is made independent as a legal unit, and as society grows increasingly complex and differentiated, the welfare state emerges and takes on almost any regulatory challenge. At this stage, law abidance becomes an important dimension of social responsibility (Holmström, 2005).

\section{LEGITIMACY THEORY}

Gray, Kouhy and Lavers (1995) have pointed out that legitimacy theory has an advantage over other theories as it provides disclosing strategies that organisations may adopt to legitimise their existence. Legitimacy theory is derived from the concept of organisational legitimacy, which has been defined by Dowling and Pfeffer (1975) as "a condition or status which exists when an entity's value system is congruent with the value system of the larger social system of which the entity is a part". As argued by Sethi (2002), public trust in corporate morality is waning fast. In the public's eyes, corporations are becoming the enemies of public interest (Castello \& Lozano, 2011). This is also the reason why corporations are seeking new forms of social legitimacy and sustainability. CSR first occurred decades ago and since then, society has developed and changed. Members of society, especially in postcommunist countries, are interested in new concepts and ideas.

The perspectives provided by legitimacy theory indicate that organisations are not considered to have any inherent right to resources, or in fact, to exist. Organisations exist to the extent that the particular society considers that they are socially legitimate, and if this is the case, the society "confers" upon the organisation that "state" of legitimacy. The idea of "legitimacy" can be directly related to the concept of a "social contract". Specifically, an organisation's survival will be threatened if 
the society perceives that the organisation has breached its social contract. Where society is not satisfied with the organisation for not operating in an acceptable or legitimate manner, then the society will effectively revoke the organisation's "contract" to continue its operations (Deegan, 2002).

Therefore, an organisation's socially responsible activities have to coincide with society's needs. It requires in-depth research on the part of an organisation to be familiar with different opinions and expectations in society. Ward indicates that legitimacy is a resource on which an organisation is dependent for survival (Ward, 2006).

Deegan (2002) and Sethi (1975) believe that under the pressure of changing societal expectations, some corporations are starting to intensify their CSR engagement by introducing new initiatives and a new rhetoric in their communication with stakeholders. CSR is becoming a fundamental way to redefine the role of business in society (Castello \& Lozano, 2011).

Suchman (1995) describes three types of legitimacy: pragmatic, cognitive, and moral. The first is "pragmatic legitimacy" that takes into account the organisation's stakeholders. This interest can be made manifest in terms of direct exchanges between the organisation and the stakeholders, or it can also involve boarder political, economic and social interdependencies. Under the pragmatic legitimacy view, stakeholders will ascribe social legitimacy to the corporation as long as they perceive that they will benefit from the company's activities. That is, by directly or indirectly receiving some kind of benefit such as a payment or through the indirect gain of corporate activities, which might lead to some societal benefit, such as innovation. Therefore it challenges corporations to persuade their stakeholders about the benefits of their products, procedures and outputs. The second type is "cognitive legitimacy" which exists when there is little question in the minds of the different actors that the corporation serves as a natural way to effect some kind of collective action. Cognitive legitimacy operates mainly at the subconscious level, making it difficult for the corporation to directly and strategically influence and manipulate perceptions. The third type is "moral legitimacy" that reflects a positive normative evaluation of the organisation and its activities. It refers to conscious moral judgments on the organisation's outputs, procedures, structures and leaders. The concept is not so much about whether a given activity benefits the evaluator, but rather on the judgments about whether the activity is "the right thing to do". Managing moral legitimacy must therefore be perceived as deliberative communication through persuasion using rational arguments (Castello \& Lozano, 2011).

Organisations should seek social legitimacy for several reasons. Suchman (1995) claims that there are two particularly important dimensions in this regard: firstly, the distinction between pursuing continuity and pursuing credibility; and secondly, the distinction between seeking passive support and seeking active support. 
Kaja Tampere

\section{CONTINUITY VERSUS CREDIBILITY}

Social legitimacy enhances both the stability and the comprehensibility of organisational activities, and stability and comprehensibility often enhance each other. However, organisational behaviours rarely foster continuity and credibility, persistence and meaning in equal measure. Social legitimacy leads to persistence because audiences are most likely to supply resources to organisations that appear desirable, proper, or appropriate (Parsons, 1961; Suchman, 1995). Socially legitimate organisations become almost self-replicating, requiring little ongoing investment in collective mobilisation. At the same time, social legitimacy affects not only how people act towards organisations, but also how they understand them. Audiences perceive a socially legitimate organisation not only as more worthy, but also as more meaningful, more predictable, and trustworthy. As Meyer and Rowan (1991) say, "organisations that lack acceptable socially legitimated accounts of their activities, are more vulnerable to claims that they are negligent, irrational and unnecessary". Continuity and credibility are usually mutually reinforcing: in most organisational settings, "shared understandings are likely to emerge to rationalise the pattern of behaviour that develops, and in the absence of such rationalisation and meaning creation, the structured patterns of behaviour are likely to be less stable and persistent" (Pfeffer, 1981; Suchman, 1995).

\section{AN ESTONIAN CASE STUDY: METHOdOLOGY AND DATA COLLECTION PROCESS}

The qualitative research method was used in the data collection process. The frame for methodology was a case study and the method was realised with semi-structured interviews.

For this research, a sample for the Estonian case study and for interviews was selected from the corporate responsibility index. This index is conducted by the Estonian CSR Forum. The Responsible Business Forum had already developed a corporate responsibility index in 2007, in cooperation with the Estonian Business School and Estonian Daily Business Newspaper. The index aims to assist companies in defining, evaluating, and monitoring their economic, social, and environmental impact. It enables companies to receive feedback and compare their results with those of other companies, thus identifying future needs for development. To participate, companies are asked to complete the evaluation questionnaire. Evaluation is very similar to that of the BITC index, following the four-part structure: business strategy, integration of CR principles, issues management, stakeholder reporting and communication. The aim of CR ranking is to recognise good performance.

Seven corporations from the Estonian 2013 corporate responsibility index research, who received the quality mark for sustainable corporation, participated in this research as respondents for interviews. There were overall 34 organisations receiving this year's quality mark. Applications to be part of this particular research 
were sent out to the 20 best corporations via e-mail. Since the results for this research were gathered through qualitative semi-structured interviews, all these 20 organisations selected were situated in Tallinn. An e-mail was sent out to organisations' communication managers. Due to the a tight working schedule, 11 organisations out of 20 reacted immediately to the request to be part of this research, 4 of them had to refuse due to a busy working schedule, and 7 agreed to be part of this research.

Data collection showed that the request to be part of this research should have been sent out to organisations earlier, because many pointed out that it is the busiest time of the year for them, and due to different projects they were not able to be part of the research. In many organisations, the communication managers did not deal with CSR activities in their organisation, and CSR management was given to other managers such as risk managers, investment directors, etc.

Seven organisations from the 2013 CSR index, who received the CSR quality mark for their socially responsible actions, were selected and participated in this research:

- Eesti Energia (Energy infrastracture R1)

- Loodusvägi OÜ (Healthy food R2)

- Pagar Võtaks OÜ (Healthy food R3)

- BaltCap Estonia (Infrastracture company R4)

- DPD Eesti AS (Post service company R5)

- Tallinna Lennujaam AS (Transport A6)

- Swedbank (Banking R7)

Interviews took place on the company premises and respondents were mostly people who are responsible for CSR activities.

The researcher planned one hour for each interview. Interviews were a combination of standardised and deeper interviews and in practice interviews were semi-structured. Generally the researcher had similar questions for all companies, but in cases when respondents were enthusiastic to talk, researcher did not stop the process and in some cases the planned standard structure of interview did not work. However, this was not a problem as researchers planned interviews which were semi-structured.

The interview results were analysed via the text analyses method, in some cases macro-level discourse analyses were also used. This was especially the case when respondents' answers were linguistically very impressive and also cases when respondents impressed some critics regarding the business situation in the state generally and about ecological production as a trend in Estonia. 
Kaja Tampere

\section{DISCUSSION AND CONCLUSIONS}

\section{CSR as a lifestyle}

In the case of food production companies, both organisations offer eco-friendly products and promote an eco-friendly lifestyle, therefore socially responsible activity is already part of the organisations and their culture. They admitted: "We have followed CSR principles since the creation of our organisation" [R2, R3]. This is a very new trend in Estonian society and differentiates us from old democracies.

\section{CSR as a part of the organisational culture}

In the case of bigger infrastructure organisations, they admitted that even though an organisation's CSR activities are ingrained into its management culture, sometimes it is hard for them to explain the implications for socially responsible behaviour, especially when taking into the consideration the fact that the majority of respondents believe that the organisation is able to be sustainable when it makes a profit. "Society holds the prejudice that an organisation is capable of making profit only in unethical ways" [R1, R6].

\section{CSR as an expectation from society}

Bigger organisations are facing the fact that because of their size, society is expecting more from them. At the same time, bigger corporations themselves are also admitting the fact that being a large corporation, they do have a greater impact on daily life and on the environment. In the case of smaller organisations, the society feels that because of their small size, they are closer to the community and therefore operate with the community. Because of their size, the society is also not expecting as much from them as they do when it comes to larger corporations.

Even though varying structures of CSR activities can be found in the marketplace, at the same time there are organisations whose CSR activities are institutionalised. It means that CSR commitment is employed liberally throughout company policies and reflects the company's commitment to demonstrating social responsibility across all stakeholder groups (Pirsch et al., 2007).

Organisations strongly believe that in order for their CSR activities to be successful and approved by the society, socially responsible activities should be rooted in an organisation's management culture. It means that the decision-making process and every action is handled within the norms and values of socially responsible behaviour. Organisations' representatives agreed that CSR activities can support an organisation's marketing purposes, but they do not believe that socially responsible activities should exclusively be part of the marketing strategy. "It is clear that CSR activities can be applied to an organisation's marketing purposes, but its deeper meaning is given by socially responsible processes handled on a daily basis" [R1, R4]. 


\section{CSR and marketing in contradiction}

Therefore, the argument that claims and shows that CSR activities are (or can be) mainly for the purpose of organisation's marketing achievements, was not proved by the organisations taking part in this research. Nevertheless, connection with CSR activities and marketing principles definitely do exist, especially when analysing CSR communication activities. Several corporations readily admit that they see CSR primarily as a vehicle to enhance or protect their reputation. Some point out that CSR communication is not always beneficial for them since it may breed scepticism. Still, it is important to acknowledge that some form of communication is actually needed. Communication is inescapable - even silence on the matter of CSR is a form of communication. There can be manipulative CSR communication, but ethical and well-planned CSR communication can provide the potential to help constitute stakeholder participation and ethical business practices (Ihlen et al., 2011).

\section{CSR for stakeholders goods}

The majority of the organisations that participated in this research admitted that they do communicate their CSR activities to their stakeholders and partners. This is done mainly for raising awareness about this concept and also bringing positive effects that customers know and can ask for products and services that are in accordance with principles of sustainable entrepreneurship.

\section{CSR communication is mainly in corporate electronic media}

As mentioned earlier, an organisation's channels for CSR communication also play an important role. The majority of respondents communicate their CSR activities mainly through their official web pages or social media platforms. CSR communication's main concept is a CSR report that is compiled annually and published on the organisation's web page. Corporations emphasise that the CSR communication channel, as well as its message, also depends on its field. For example, Swedbank's AS [R7] representative admits that their organisation mainly uses its official channels (such as the web page, newsletters, press releases and social media platforms), but in case of some projects, the marketing department also handles some communication activities. One representative also admitted that CSR communication messages, as well as the channel and target depend on the activity. Pagar Võtaks OÜ's [R3] representative said that their organisation does not do annual reports on their CSR activities, instead they hope that its responsible behaviour is noticed by society by believing that Pagar Võtaks OÜ offers eco-products and is promoting eco-friendly products.

\section{CSR management and communication management}

When it comes to analysing which organization department is handling CSR activities, research showed that only two organisations (Swedbank AS and Eesti Energia) have CSR management as part of the communication department's function. As 
meeting the expectations and needs of organisational stakeholders is an important aspect of CSR, the organisation's PR department should therefore handle its CSR activities. As Grunig and Hunt (1984) explain, public relations personnel perform a boundary role - they function at the edge of the organisation, serving as a liaison between the organisation and the external or internal groups or individuals. This means that the public relations professional is the one who knows the expectations and needs of stakeholders as well as the society-at-large. Research showed that CSR activities are mainly divided between departments by the content of CSR activity. A representative of large enterprise said that: "CSR activities that affect our employees are managed by the personnel department; environmental policy is managed by the department of real estate; customer satisfaction-related CSR activities are handled by the marketing and personnel department", Swedbank AS [R7], adding that being a large organisation, it is almost impractical that CSR activities are managed by one department. BaltCap [R4], Estonia AS, Loodusvägi OÜ [R2], and Pagar Võtaks OÜ [R3], admitted that they are small companies and therefore they do not have separate departments to deal with CSR activities. "As a small company with only 20 employees, we do not have separate departments in our organisation. CSR activities are managed by the office manager who also assists the board of directors", [R3] said one representative of a smaller enterprise. In CSR positioning, organisations followed the idea of what socially responsible behaviour means for them and what is the desired effect of their CSR activities. In addition, larger corporations followed the idea that because of their size, they have an impact on the social, marketing and natural environment, therefore it is important to cover all those fields in CSR activities.

\section{The position and role of CSR in organisations}

When it comes to an overall analysis of CSR's position in an organisation, the research showed that all companies that participated agreed that CSR principles should first and foremost be planted in the management culture. However, when analysing CSR activity management in an organisation, it seems that organisations have different approaches as to which department should handle CSR. Grunig and Hunt (1984) believe that because an organisation's public relations professionals are the closest to society and act as a boundary between the organisation and society, they are familiar with their expectations and needs. This can lead to an understanding that public relations departments should handle CSR activities. This also applies when considering the idea that the CSR concept is about meeting society's needs and taking responsibility for the organisation's actions that influence social wellbeing. One respondent said: "Being responsible for stakeholders and society at large is nowadays an integral part of business activities" [R6]. DPD Eesti AS's [R5], representative explains that CSR management is part of the personnel department, even though the majority of their CSR activities are directed at the community, environment, and market environment, but of course also the working environment. Still, 
an organisation's representative points out that "an organisation and its employees are part of the community and therefore cannot be considered separately" [R5]. However, this and Grunig and Hunt's (1984) idea about CSR management, can lead us to the conclusion that as an organisation and its employees are part of the community and cannot be considered separately, the public relations department should manage an organisation's CSR activities. The argument that one organisational department cannot handle CSR activities definitely needs further research, as this thesis does not hold enough outlooks and theories on this statement. Research showed that in most organisations, CSR management is not positioned in the public relations department. Therefore it could be said that organisations are not considering public relations as a management tool or do not see the importance of the public relations manager.

\section{CSR and an organisation's social legitimacy}

Findings showed that organisations' ideas about social legitimacy mainly coincide with the definition by Dowling and Pfeffer (1975) which indicates that social legitimacy "is a condition or status, which exists when an entity's value system is congruent with the value system of the larger social system of which the entity is a part. When a disparity, actual or potential, exists between the two value systems, there is a threat to the entity's legitimacy" (Ward, 2006). Organisations that were willing to define social legitimacy, saw it as "social approval", that guarantees an organisation's reputation and positive public opinion. Social legitimacy was also argued by Shocker and Sethi (1973), as: "any social institution - and business with no exception - operates in a society via social contract, expressed or implied, whereby its survival and growth are based on: a) the delivery of some socially desirable ends to society in general; and b) the distribution of economic, social or political benefits to groups from which it derives its powers" (Ward, 2006). The idea relies on the notion that there is a "social contract" between a company and the society in which it operates. Also social legitimacy was seen as trust towards organisation and willingness to consume their products and services. "Transparency" was also seen as an aspect of social legitimacy, where social legitimacy was still defined by the organisational point of view. Whereas some organisations' representatives had not advised the idea behind the social legitimacy concept, they also were not liable to define it. This can actually be explained in many different ways. First, those organisations do not recognise the need to start justifying socially responsible activities for the recognition of social legitimacy. When organisations do not have social legitimacy (acceptance from the society), their activities are not acceptable and approved by their stakeholders. Therefore, they cannot be sustainable when taking into consideration the idea that an organisation is sustainable when it is able to handle its resources in a responsible way to ensure organisational operation in the future. Social responsibility is first and 
foremost part of an organisation because it implies that the corporation should take responsibility for its actions and the impact it has in the society. Therefore research has shown that despite the financial crises, many organisations neither recognise the concept nor the importance of social legitimacy. The second reason can be that social acceptance was not defined as social legitimacy, but as sustainability among some participants. The important aspect here is to recognise that social legitimacy and sustainability cannot both be defined equally, however, one assures the other and the idea behind both concepts is relatively similar. Dowling and Pfeffer (1975) indicate that social legitimacy is a resource on which an organisation is dependent for survival. It means that social legitimacy is society's approval towards an organisation's activities. And social legitimacy therefore ensures the corporation's sustainability. When the society does not approve an organisation's activities and members of society are able to get similar products and services from competitors whose actions are approved by society, it hinders the operations of the disproved company. The third reason can be that even though organisations communicate their socially responsible activities to stakeholders, organisations are still unsure if people are interested in CSR reports. When organisations are not sure how the society feels about their socially responsible activities, they are also unable to determine whether their CSR activities ensure social legitimacy or not. The fourth reason can be related to the notion that organisations have started to deal with the CSR concept more seriously during the years 2008-2011. Although all organisations admitted that CSR activities have been part of their business activities since the early 2000s, more serious actions towards this end started some years ago. More aware actions towards CSR activities were made in the years 2008-2011 and therefore organisations have not truly defined what socially responsible actions ensure, or how can an organisation's sustainability be provided by social legitimacy. Although the legitimacy theory was established more than 30 years ago, the concept is fairly new and unfamiliar among organisations. The fifth reason is related to how CSR management is positioned in an organisation. The majority of organisations admitted that the public relations department does not manage the organisation's CSR activities. Research showed that as different departments, for example the personnel department or risk department, etc., manage CSR, it therefore can be argued that some participants did not recognise the social legitimacy aspect in their CSR activities because they do not face the social legitimacy aspect in their daily work assignments or they lack professional expertise regarding this concept. Organisations where CSR management was positioned in the PR department, mainly recognised the concept and were able to define social legitimacy. The organisations willing to define social legitimacy or acknowledge it to any degree, mainly saw social legitimacy as social approval, which was also the main aspect in the definition by Dowling and Pfeffer (1975). However, there were also representatives who did not recognise the social aspect, but saw it as knowledge that their activities are fair 
and transparent. Organisations that acknowledge social legitimacy to any degree, also acknowledge that social legitimacy is an important aspect in their ability to operate. They see CSR as a tool for ensuring social legitimacy, but emphasise that the question about social legitimacy should be considered as a whole. It means that "as long as social responsibility and sustainability are reviewed separately from business activities, there are limited opportunities to ensure social legitimacy", as said by one representative of Swedbank AS [R7]. This in turn shows that in order for an organisation to gain social legitimacy and organisational sustainability, it needs to operate within the norms and expectations of the society. By engaging with CSR principles and making socially responsible decisions, the corporation guarantees acceptance in the society and therefore social sustainability that in turn guarantees social legitimacy. It is also important to emphasise that an organisation's socially responsible actions guarantee social legitimacy and organisational sustainability, when CSR principles are planted into the management. An organisation's socially responsible actions are mainly recognised and appreciated when they are part of what the organisation is, and what it represents. Society tends to be sceptical towards those whose actions and allegations do not match - it means those organisations that claim to be socially responsible but do not extend the principles of social responsibility with their actions. Mainly it can be said that the organisations that acknowledged social legitimacy, apprehend social approval in social legitimacy as the legitimacy concept is mainly used in the legislative field.

\section{The age of CSR}

All in all, the research showed that organisations recognise the importance of socially responsible activities. They believe that nowadays the aim of organisations is much more than just profit-making. Still, when considering Friedman's (1970) argument that an organisation has only one social responsibility and that is to make profit, organisations seems to agree with this argument, to some extent. They note that when an organisation is effective it can start contributing to the community's welfare. As there are many different aspects of CSR and also different organisations with different activities, there are also many ways in which CSR activities are conducted. Research has shown that organisations mainly contribute to their occupation sphere. They recognise that their operational activities have a great impact on societal, environmental, and economic aspects. This means that in order to be sustainable, an organisation needs to invest into those societal, environmental and economic aspects, making sure that given resources are handled responsibly, and that the organisation is able to produce in the future. All organisations emphasised that in order to avoid society's scepticism towards an organisation's socially responsible activities, CSR principles should be part of the organisation's management culture. Organisations should define themselves through socially responsible behaviour and at the same time make decisions based on the principles of CSR. 


\section{CSR and public relations in the management context}

However, when analysing in which department CSR activities are managed, research has shown that most organisations take into account the occupation of CSR activity in their management. For example, in the case of Tallinna Lennujaam AS [R6], where CSR activities concerning the organisation's personnel are managed by the personnel department, customer and employee satisfaction is handled by the personnel and marketing department, etc. This can imply several things. Firstly, the organisations did not consider the overall aspect of CSR and what their primary goal with CSR is. When considering two arguments - firstly, the argument that CSR is meeting the expectations and needs of the society and operating responsibly with the resources given, and secondly, that the public relations department is acting as a boundary between the organisation and the society - it helps to explain CSR management appropriateness in the public relations department. At the same time, when following a more European approach to CSR which concentrates more on responsible activities towards employees, it can be said that since the organisation's responsible activities focus on employees, its management should be in the personnel department, because they act as a boundary between the organisation and its employees. Secondly, when it comes to large corporations there is the case that since there are many different CSR activities, the public relations department is not capable of handling it. The statement can nevertheless argue the reason that an organisation's employees and the organisation itself is part of the community and therefore cannot be treated separately. This brings us still to the notion that an organisation's responsible behaviour is in one way or another social, therefore CSR management should be done by the public relations department. This is because CSR activities will be communicated to the society, and in one way or another, public relations activities are part of the "management of communication between an organisation and its publics" (Grunig \& Hunt, 1984). An interesting notion that this research also showed, was that social legitimacy was acknowledged by those organisations whose CSR activities were managed by the department. Therefore, respondents also realise the social legitimacy aspect behind an organisation's CSR activities.

\section{The new coming of the concept of social legitimacy}

To sum up the results on social legitimacy and how organisations recognise this concept, it seems that despite the fact that social legitimacy theory was developed more than 30 years ago, the concept seems fairly new and unfamiliar for most respondents in this research. Nevertheless, organisations that have acknowledged social legitimacy also believe that CSR activities can ensure social legitimacy. They believe that social legitimacy should be considered as a whole with the organisation's sustainability and responsible behaviour. Also emphasising that to ensure social legitimacy, the organisation's CSR activities should definitely be part of the 
management culture - socially responsible statements have to be in accordance with the organisation's actions.

\section{CSR and social legitimacy in the context of post-communist countries}

During the past few years, CSR has definitely developed in post-communist countries, including in Estonia. Organisations realise that their function in the society is not just business-related and aimed at making profit, but also thinking about how resources are used. It is important that organisations operate in the norms of socially responsible principles and ensure that their actions and decisions are not only beneficial for them, but also take into consideration the stakeholders and the society. Organisations are not only acknowledging the importance of engaging with CSR activities, but also starting to see the beneficial side of socially responsible actions for the organisation's sustainability.

In this research, social legitimacy is used to explain the need for socially responsible behaviour. Legitimisation is treated as the perceived need to gain acceptance in society, because without the stakeholder's acceptance, organisations will not be able to be sustainable nor gain new spheres of power to grow. Acknowledging social legitimacy, organisations should lead to strive for compliance with the norms and values of socially responsible behaviour.

\section{CSR as a potential new role for public relations}

CSR communication and management are important aspects that need to be considered when dealing with CSR. Since there is scepticism towards why organisations act in a socially responsible way, there is a need to make sure that CSR activities are communicated and managed in a way that is clear to stakeholders as well as for the society.

Grunig and Hunt have treated public relations as "management of communication between the organisation and its publics" (1984). Therefore, this paper suggests that an organisation's public relations department should handle CSR activities, mainly because public relations departments act as an intermediary with the society and therefore are aware of what are society's expectations and deficiencies. The majority of participants in this research attest that they believe CSR should be considered as a management tool and part of the overall decision-making process. However, few of the respondents admitted that CSR management is part of their organisation's public relations department. Research has shown that the department to whom the CSR activity belonged, managed CSR activities. For example, the personnel department managed CSR activities that affect an organisation's employees, etc. Also, the company's size influences how CSR is managed. Small companies admitted that because of their size, they often do not have departments and therefore CSR is managed by different positions. For example, a BaltCap AS representative admitted that the office manager deals with CSR activities in their organisation. 
Present research has shown that although organisations acknowledge the growing need for socially responsible behaviour, they are not realising the social legitimacy aspect behind CSR activities. The majority of respondents did acknowledge that being socially responsible is vital for an organisation's sustainability. The social legitimacy aspect was a fairly new concept for the organisations participating in this research. Social acceptance was not defined as social legitimacy among most of the respondents, but as sustainability. The important aspect here is to recognise that social legitimacy and an organisation's sustainability cannot both be defined equally, however, one warrants the other. Organisations, however, had a solid understanding that CSR activities can ensure social legitimacy, and therefore an organisation's sustainability.

\section{REFERENCES}

Brusseau, J. (2011). The Responsible Office: Corporations and Social Responsibility: The Business Ethics Textbook. Retrieved October 12, 2017 from http://catalog.flatworldknowledge.com/ bookhub/ reader $/ 1695$ ?e=bru sseau-ch13_s02.

Castello, I., \& Lozano, J. M. (2011). Searching for new forms of legitimacy through corporate responsibility rhetoric. Journal of Business Ethics, 100(1), pp. 11-29.

Deegan, C. (2002). Introduction: The legitimizing effect of social and environmental disclosures - a theoretical foundation. Accounting, Auditing \& Accountability Journal, 15(3), pp. 282-311.

Dowling, J., \& Pfeffer, J. (1975). Organizational legitimacy: Social values and organizational behavior. Pacific Sociological Review, 18, pp. 122-136.

Friedman, M. (1970). The social responsibility of business is to increase its profits. New York Times Magazine.

Gray, R., Kouhy, R., \& Lavers, S. (1995). Corporate social and environmental reporting: A review of the literature and a longitudinal study of UK disclosure. Accounting, Auditing \& Accountability Journal, 8, pp. 47-77.

Grunig, J. E., \& Hunt, T. (1984). Managing Public Relations. New York, NY: CBS College Publishing.

Holmström, S. (2005). Co-evolution of society and organization: Reflexivity, contingency and reflection. Organizational Legitimacy and the Public Sphere, 1, pp. 54-72.

Ihlen, O., Bartlett, J., \& May, S. (2011). The Handbook of Communication and Corporate Social Responsibility. Hoboken, NJ: Wiley-Blackwell.

Meyer, J. W., \& Rowan, B. (1991). Institutionalized organizations: Formal structure as myth and ceremony. In: W. W. Powell \& P. J. DiMaggio (eds.), The New Institutionalism in Organizational Analysis. Chicago: University of Chicago Press, pp. 41-62.

Morsing, M., \& Schultz, M. (2006). Corporate social responsibility communication: stakeholder information, response and involvement strategies. Retrieved April 3, 2014 from http://www.glerl.noaa.gov/ seagrant/ClimateChangeWhiteboard/Resources/Uncertainty/climatech/morsing06PR.pdf.

Parsons, T. (1961). Structure and process in modern societies. American Journal of Sociology, 66(6), pp. 616-617.

Pfeffer, J. (1981). Management as symbolic action: The creation and maintenance of organisational paradigms. In: B. S. L. Cummings (ed.), Research in Organizational Behavior, Vol. 3. Greenwich: CT JAI Press, pp. 1-52.

Pirsch, J., Gupta, S., \& Grau, S. L. (2007). A framework for understanding corporate social responsibility programs as a continuum: An exploratory study. Journal of Business Ethics, 70, pp. 125-140. 
Sethi, S. P. (1975). Dimensions of corporate social responsibility. California Management Review, 17(3), pp. 58-64.

Sethi, S. P. (2002). Standards for corporate conduct in the international arena: Challenges and opportunities for multinational corporations. Business and Society Review, 107(1), pp. 20-40.

Shocker, A. D., \& Sethi, S. P. (1973). An approach to incorporating social preferences in developing action strategies. California Management Review, Summer, pp. 97-105.

Suchman, M. C. (1995). Managing legitimacy: Strategic and institutional approaches. Academy of Management Review, 20(3), pp. 577-585. Retrieved December 29, 2013 from http://amr.aom.org/ content/20/3/571.full.pdf+html.

Tampere, K. (2013). The scope and limit for the development of social responsibility in the Baltic States as a strategy of corporate communication. Central European Journal of Communication, 6 , pp. 293-307.

Ward, L. (2006). Legitimacy theory: A story of reporting social and environmental matter within the Australian food and beverage industry. Retrieved October 12, 2017 from http://csringreece.gr/files/ research/CSR-1290000469.pdf?user=bd31a3168ebac47053af2648943f5351. 